\title{
Effect of cilostazol in experimental model of degloving injuries in rat limbs ${ }^{1}$
}

\author{
André Pazio', Vital Burko Santos", Guataçara Schenfelder Salles Junior ${ }^{\prime \prime \prime}$
}

'MD, Resident, Division of Plastic Surgery, Department of Surgery, Clinics Hospital, Universidade Ferederal do Paraná (UFPR), Curitiba-PR, Brazil. Scientific and intellectual content of the study, analysis and interpretation of data, technical procedures, statistical analysis, manuscript preparation and writing.

"Graduate student, Pontifícia Universidade Católica do Paraná (PUC-PR), Curitiba-PR, Brazil. Acquisition, analysis and interpretation of data; technical procedures; manuscript preparation.

"IIPhD, Associate Professor, Experimental Surgery Division, School of Medicine, PUC-PR, Curitiba-PR, Brazil. Scientific, intellectual, conception and design of the study; critical revision; final approval.

\begin{abstract}
Purpose: To evaluate the effect of the cilostazol on the evolution of partially avulsed flaps, using experimental model of cutaneous degloving in rat limbs.

Methods: A controlled and randomized experimental study was carried out in which the blood flow and the percentage of flap necrosis were evaluated. We compared the study group, which received cilostazol, and the control group, which received enteral saline solution in the postoperative period. The blood flow in the flap was evaluated through Laser Doppler flowmetry, and a planimetry using the IMAGE J software was employed for the calculation of the area of necrosis.

Results: Enteral administration of cilostazol was associated with a higher mean blood flow in all regions of the flap, with a statistically significant difference in the proximal and middle regions $(p<0.001)$ and a lower percentage of necrotic area in the flap $(p<0.001)$.

Conclusion: Postoperative enteral administration of cilostazol increased blood flow and decreased the total area of necrosis of avulsed cutaneous flaps of rat limbs.

Key words: Cilostazol. Degloving Injuries. Ischemia. Rats.
\end{abstract}




\section{Introduction}

Degloving injuries, also called partial avulsions, are lesions that cause separation of skin and subcutaneous tissue from the underlying muscle and fascia. Most degloved injuries occur on the extremities and chest, and are caused when the tissue is trapped between a fixed surface and a moving object, such as a road pavement and the wheel of a car $^{1,2}$. Such injuries are more frequent in the young male population (male $=61.9 \%$, mean age $=32.5$ years), generating a high cost to society in relation to working days missed and treatment-related costs ${ }^{3}$.

The unbroken skin is the first defense against invasion of the body by external bacterial agents. A patient with avulsed skin loses this natural barrier, resulting in loss of plasma, blood, electrolytes and liquids, opening the door for infection, and often leading the patient to death. For this reason, it is necessary to quickly restore the skin barrier function and avoid such complications ${ }^{4}$.

Physiologically, after a period of hypo perfusion or ischemia, the tissue produces several proinflammatory and angiogenic cytokines for a better tissue perfusion. To improve this physiological reaction, researchers have tested different drugs. However, no conclusion has been reached on the best drug to increase tissue perfusion' nor is there a consensus on the best management and treatment for these lesions ${ }^{5}$.

Cilostazol is a drug that exerts selective and potent inhibition of type III phosphodiesterase, causing an increase in cAMP in platelets, smooth muscle cells and endothelial cells, and is classified as a vasodilator and antithrombotic agent ${ }^{6}$. Through its antithrombotic effect, it also reversibly inhibits platelet aggregation. Cilostazol has a faster onset (4 hours) and a shorter duration (48 hours) than salicylic acid ${ }^{7}$. Its main side effects are diarrhea, headache and dizziness, and it's contraindicated in patients with congestive heart failure. It is traditionally used in the treatment of patients with intermittent claudication secondary to chronic obstructive arterial disease who do not present pain at rest or tissue necrosis. In these patients, Cilostazol improves the distance patients can walk without pain ${ }^{7,9}$. However, to date, there are no studies on its impact on the evolution of degloving flaps.

\section{Methods}

The study was performed at Laboratory of Operative Technique and Experimental Surgery, Pontifícia Universidade Católica do Paraná, and in accord with Brazilian law the Council for International Organization of Medical Sciences-CIOMS.

For the experiment, 30 male rats of the lineage Wistar (Rattus norvegicus albinus, Rodentia mammalia), with age ranging from 10 to 12 weeks and weight varying from 250 to 320 grams were distributed in two groups (control and experimental) with 15 animals each. The rats were housed in individual containers, kept in a controlled warm environment to avoid hypothermia, receiving water and feed ad libitum and submitted to light/dark periods of $12 / 12$ hours.

The animals were submitted to general anesthesia by intramuscular administration of $75 \mathrm{mg} / \mathrm{kg}$ of Ketamine (Bayer ${ }^{\circ}$ ) and $10 \mathrm{mg} / \mathrm{kg}$ of Xylazine (Bayer ${ }^{\circ}$ ). Next, the right hind limb and inguinal region were shaved, followed by a circumferential incision at the base of the thigh, covering skin and subcutaneous tissue (Figures 1 to 3). Four Backaus hooks were positioned at the distal edge of the incision (in the anterior, posterior, lateral and medial quarters of the limb), and the degloving of the skin and subcutaneous flaps was performed by means of distal progressive traction sufficient 
to perform partial avulsion up to the ankle region, at the height of the distal third of the animal's paw (Figure 4). After 5 minutes the flap was repositioned to its original bed, with subsequent suturing of the skin with 5-0 nylon stitches (Mononylon, Ethicon'). Finally, topical antibiotic Rifamycin (Neoquimica') was sprayed on the surgical wound and the animal was housed in an individual container.

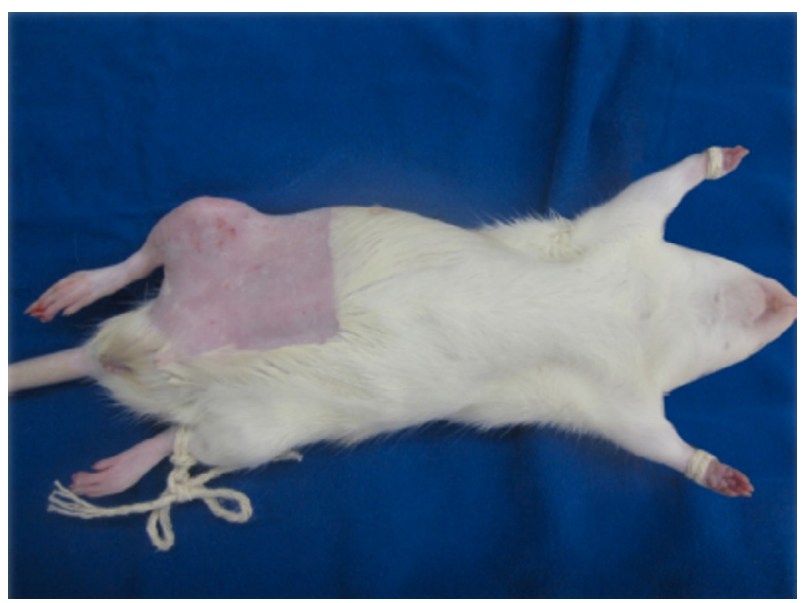

Figure 1 - Example of the one of the rats used in the study after general anesthesia and shaving of the area to be manipulated.

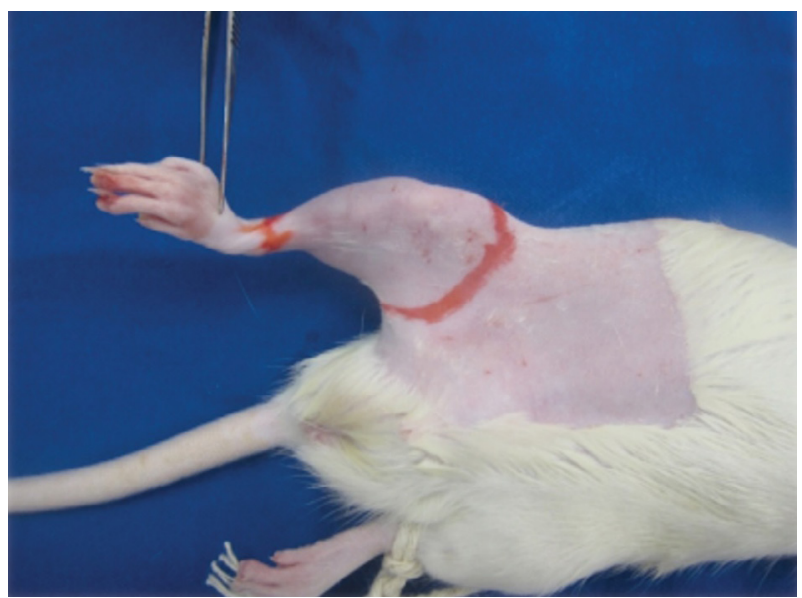

Figure 2 - Circumferential marking at the base of the thigh and ankle region at the distal third in the leg of the animal.

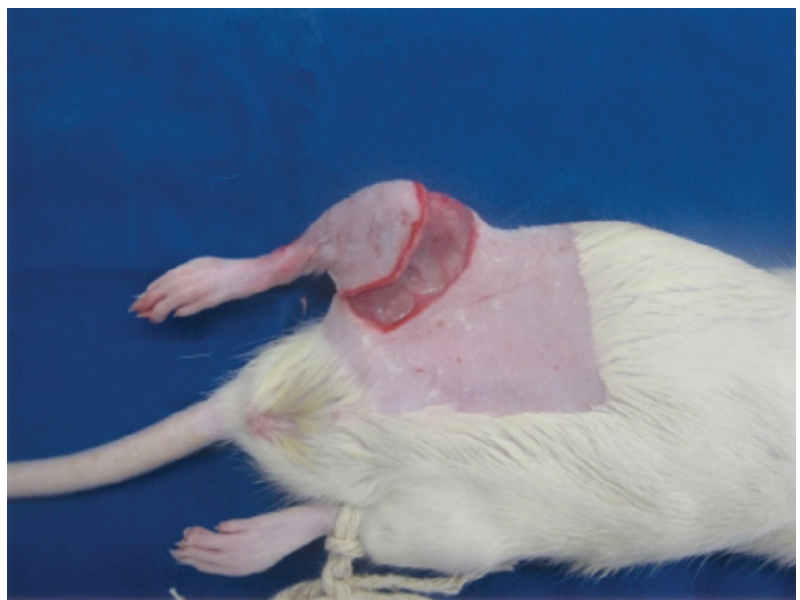

Figure 3 - Incision at the base of the thigh, full circumference, covering skin and subcutaneous tissue.

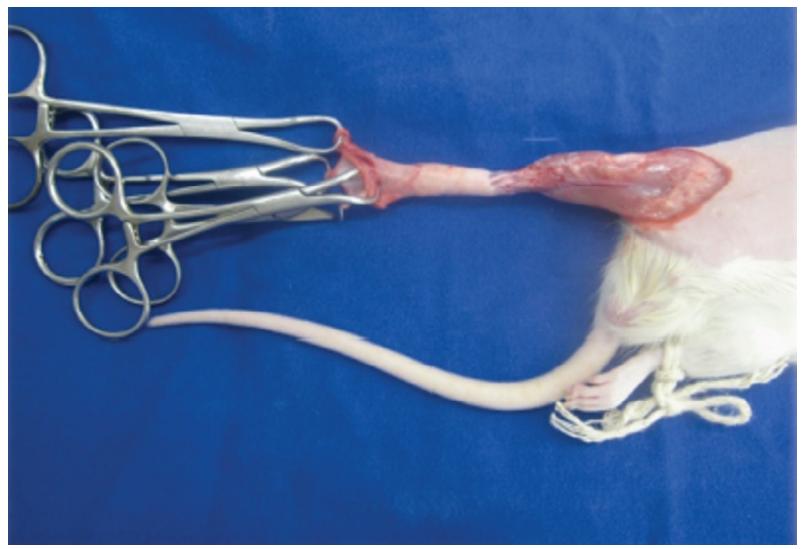

Figure 4 - The degloving of the skin and subcutaneous flap was accomplished through the progressive pulling by four Backaus hooks positioned at the distal edge of the incision.

In the immediate postoperative period, the animals received the analgesic drug dipyrone at a dose of $30 \mathrm{mg} / \mathrm{kg}$ orally to avoid pain and suffering.

The rats were then divided into two groups, each group containing 15 animals as listed below:

a) CONTROL group: One $\mathrm{ml}$ of saline solution was injected via orogastric tube immediately after suturing of the surgical wound and then twice a day for seven days ( $n=15)$. 
b) STUDY group: $10 \mathrm{mg} / \mathrm{kg}$ of Cilostazol (Vasogard, Eurofarma ) diluted in 1 $\mathrm{ml}$ of saline solution were injected via orogastric tube immediately after surgical wound suture and twice daily for the following seven days $(n=15)$.

In both groups the flap was observed daily for signs of viability or non-viability (skin color, capillary filling, ischemia, congestion or necrosis), and surgical complications (hematoma, wound dehiscence and infection).

The animals were observed daily until the 7th postoperative day, when they were sacrificed through a lethal dose $(150 \mathrm{mg} / \mathrm{kg})$ of intraperitoneal thiopental (Cristália ${ }^{\circ}$.

Exclusion criteria were the occurrence of transoperative or postoperative death and the presence of total or partial autophagy of the flap in the postoperative period.

The flap evaluation was performed by two methods: laser Doppler flowmetry for measurement of flap blood flow and planimetry to calculate the flap necrotic area.

The cutaneous flap was divided into 4 portions (proximal, middle and distal and distal) and at two points (lateral and medial). From each of these portions the blood flow was observed using laser Doppler flowmetry. The analysis was done by detecting red blood cell flow, and measured per $\mathrm{ml}$ of blood flowing in one minute, divided by 100 grams of tissue $(\mathrm{ml} / \mathrm{min} / 100 \mathrm{~g})^{10,11}$.

The final evaluation of the area of necrosis was performed through resection of the flap throughout its length, followed by planning of the flap alongside a scale in centimeters. A digital photograph with fixed focal length and without flash was taken in both groups.

The image taken from each animal was computer-processed and analyzed with the IMAGE J software (Image J version 1.48 for Windows. Wayne Resband Institute of Health,
USA), which quantifies the total area of the flap and the percentage of necrotic tissue.

Results obtained from quantitative variables were described by means, medians, minimum values, maximum values and standard deviations. For comparison of both groups (control and study) concerning necrotic area percentage, Student's t-test was employed for independent samples. The comparison of blood flow in each of the regions (proximal, middle, distal and distal) was made using the covariance analysis model (ANCOVA) including the percentage of necrotic area as covariate. For comparison of regions within each group, a variance analysis model with repeated measures was employed. A LSD (Least Significant Difference) test was used for multiple comparisons. For evaluating the association between percentage of necrotic area and blood flow, the Pearson correlation coefficient was used. The variables normality condition was evaluated through a KolmogorovSmirnov test. $P$ values $<0.05$ indicated statistical significance. The data were analyzed using the IBM SPSS Statistics v.20 software.

For each of the variables, we tested the null hypothesis that the control group mean is equal to the Cilostazol group mean, versus the alternative hypothesis of different means.

\section{Results}

No surgical complications or autophagy of the operated limb were observed. One of the animals in the study group died on the 7th postoperative day during sedation for the Doppler flowmetry of the flap and was excluded from the analysis.

Comparison of groups in relation to total area, necrotic area and percentage of necrotic area

Table 1 presents descriptive statistics of the variables according to the groups and the $p$ values of statistical tests. 
Table 1 - Comparison of groups in relation to total area, necrotic area and percentage of necrotic area.

\begin{tabular}{llccccc}
\hline & Group & $\mathbf{n}$ & Mean & Median & Standard deviation & Value of $\boldsymbol{p}^{*}$ \\
\hline Total area & Control & 15 & 649.1 & 595.3 & 174.9 & \\
& Study & 14 & 677.7 & 598.3 & 205.1 & 0.688 \\
\multirow{2}{*}{ Necrotic area } & Control & 15 & 296.8 & 289.7 & 110.4 & \\
& Study & 14 & 119.2 & 85.5 & 84.4 & $<0.001$ \\
\multirow{2}{*}{ Percentage of necrotic area } & Control & 15 & 45.9 & 44.9 & 10.2 & \\
& Study & 14 & 16.6 & 14.4 & 6.7 & $<0.001$ \\
\hline
\end{tabular}

The study group presented a smaller area and corresponding percentage of necrosis than the control group, with statistical significance $(p<0.001)$ (Figure 5$)$. There was no statistical difference in the total flap area when the two groups were compared.

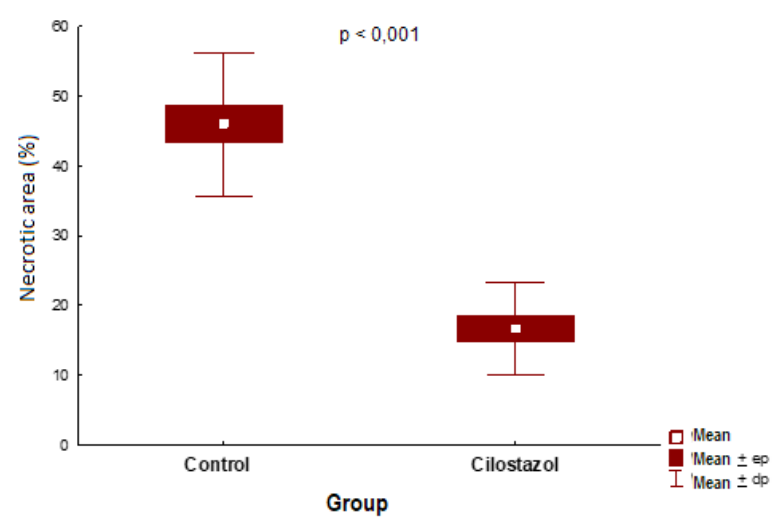

Figure $\mathbf{5}$ - Representation of the necrotic areas in both groups.

Evaluation of correlation between the percentage of necrosis and blood flow

Table 2 shows the estimated values for the Pearson correlation coefficient between the percentage of necrotic area and blood flow in each region, and the $p$ values of statistical tests.
Table 2 - Pearson correlation coefficient values between percentage of necrotic area and blood flow in each region.

\begin{tabular}{lcc} 
Region & $\begin{array}{c}\text { Pearson correlation } \\
\text { coefficient }\end{array}$ & $\begin{array}{c}\text { Value de } \\
\mathbf{p}\end{array}$ \\
\hline Proximal & -0.84 & $<0.001$ \\
Medial & -0.84 & $<0.001$ \\
Distal medial & -0.69 & $<0.001$ \\
Distal & -0.50 & 0.005 \\
\hline
\end{tabular}

For the four regions evaluated, the results indicate that there is a significant correlation between the percentage of necrotic area and blood flow. Negative correlation coefficients indicate that there is an inverse association between the percentage of necrotic area and blood flow, that is, low values (high) for the percentage of necrotic area correspond to high values (low) for blood flow.

In Figures 6 to 9, scatter diagrams for the percentage of necrotic area and blood flow are presented for the four regions evaluated.

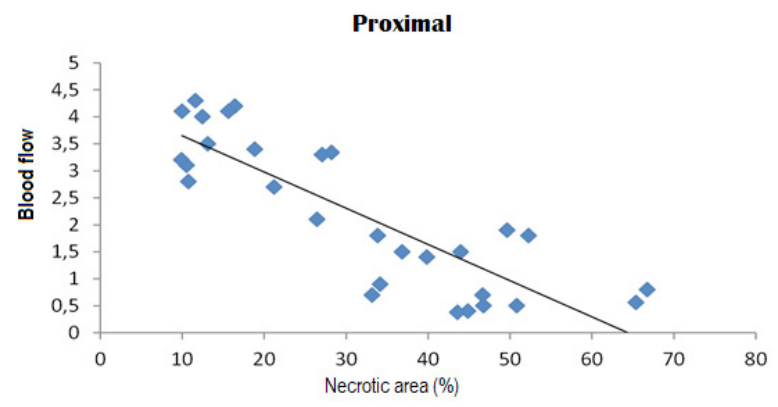

Figure 6 - Scatter diagrams for the percentage of necrotic area and blood flow in the proximal region. 


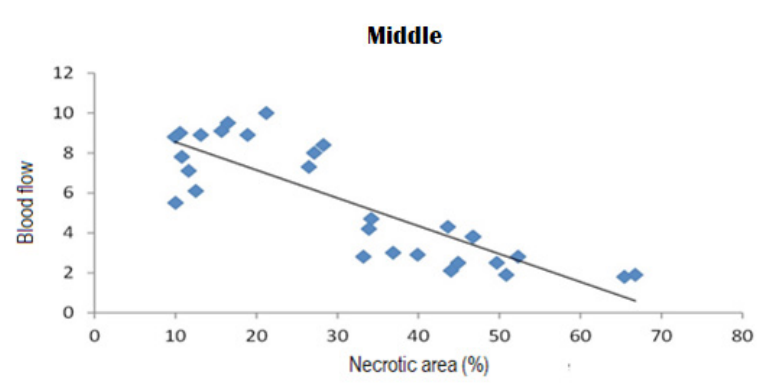

Figure 7 - Scatter diagrams for the percentage of necrotic area and blood flow in the middle region.

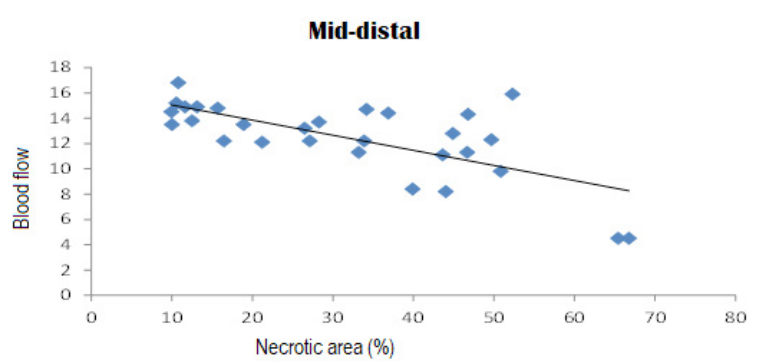

Figure 8 - Scatter diagrams for the percentage of necrotic area and blood flow of the mid-distal region.

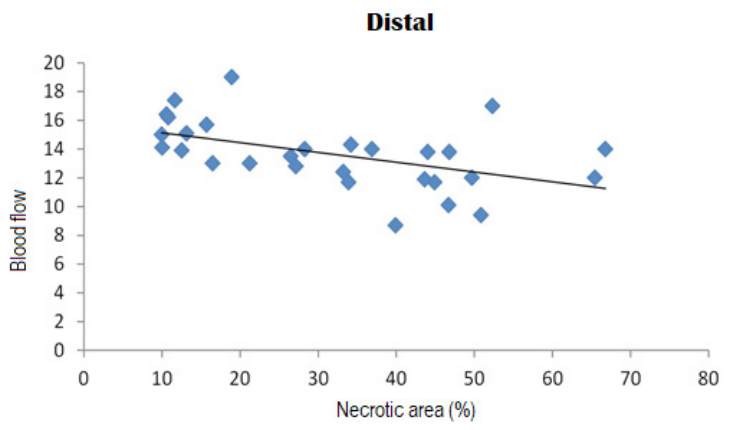

Figure 9 - Scatter diagrams for the percentage of necrotic area and blood flow of the distal region.

\section{Comparison of groups in relation to blood flow (Doppler)}

Table 3 shows, for each region, descriptive statistics of blood flow by group. The values of $p$ for statistical tests are also shown.

Table 3 - Blood flow by group for each of the regions.

\begin{tabular}{|c|c|c|c|c|c|c|}
\hline \multirow{2}{*}{ Region } & \multirow{2}{*}{ Group } & \multicolumn{4}{|c|}{ Blood Flow } & \multirow[b]{2}{*}{ Value of $p^{*}$} \\
\hline & & $\mathbf{n}$ & Mean & Median & Standard Deviation & \\
\hline \multirow[t]{2}{*}{ Proximal } & Control & 15 & 1.02 & 0.80 & 0.56 & \\
\hline & Study & 14 & 3.44 & 3.37 & 0.65 & $<0.001$ \\
\hline \multirow[t]{2}{*}{ Middle } & Control & 15 & 3.00 & 2.80 & 0.95 & \\
\hline & Study & 14 & 8.17 & 8.60 & 1.29 & $<0.001$ \\
\hline \multirow[t]{2}{*}{ Mid-distal } & Control & 15 & 11.05 & 11.30 & 3.46 & \\
\hline & Study & 14 & 13.95 & 13.75 & 1.33 & 0.144 \\
\hline \multirow[t]{2}{*}{ Distal } & Control & 15 & 12.45 & 12.00 & 2.13 & \\
\hline & Study & 14 & 14.94 & 14.55 & 1.83 & 0.204 \\
\hline
\end{tabular}

The avulsed flaps in the study group showed greater blood flow in the proximal and medial regions when compared to the same flap regions in the control group $(p<0.001)$. No statistically significant difference was found in the blood flow for the distal medial and distal regions in the flaps of both groups (study and control).
Comparison of regions evaluated in flowmetry within each group

In both groups (study and control) blood flow was consistently greater as it progressed distally in the flap $(p<0.001)$. However, when comparing the same flap region in both groups, the blood flow in the study group was higher in each of the regions studied (Table 4). 
Table 4 - Comparison of groups in relation to blood flow in each of the areas.

\begin{tabular}{|c|c|c|c|c|c|c|c|c|}
\hline \multirow[b]{2}{*}{ Group } & \multicolumn{8}{|c|}{ Blood Flow } \\
\hline & Region & $\mathbf{n}$ & Mean & Median & Minimum & Maximum & $\begin{array}{l}\text { Standard } \\
\text { Deviation }\end{array}$ & Value of $p^{*}$ \\
\hline \multirow[t]{4}{*}{ Control } & Proximal & 15 & 1.02 & 0.80 & 0.38 & 1.90 & 0.56 & \\
\hline & Middle & 15 & 3.00 & 2.80 & 1.80 & 4.70 & 0.95 & \\
\hline & Mid-distal & 15 & 11.05 & 11.30 & 4.50 & 15.90 & 3.46 & \\
\hline & Distal & 15 & 12.45 & 12.00 & 8.70 & 17.00 & 2.13 & $<0.001$ \\
\hline \multirow[t]{4}{*}{ Study } & Proximal & 14 & 3.44 & 3.37 & 2.10 & 4.30 & 0.65 & \\
\hline & Middle & 14 & 8.17 & 8.60 & 5.50 & 10.00 & 1.29 & \\
\hline & Mid-distal & 14 & 13.95 & 13.75 & 12.10 & 16.80 & 1.33 & \\
\hline & Distal & 14 & 14.94 & 14.55 & 12.80 & 19.00 & 1.83 & $<0.001$ \\
\hline
\end{tabular}

*ANCOVA with repeated measures, $p<0.05$

The flow diagram depicted in Figure 10 compares the blood flow in each of the regions in the two groups analyzed (control and study).

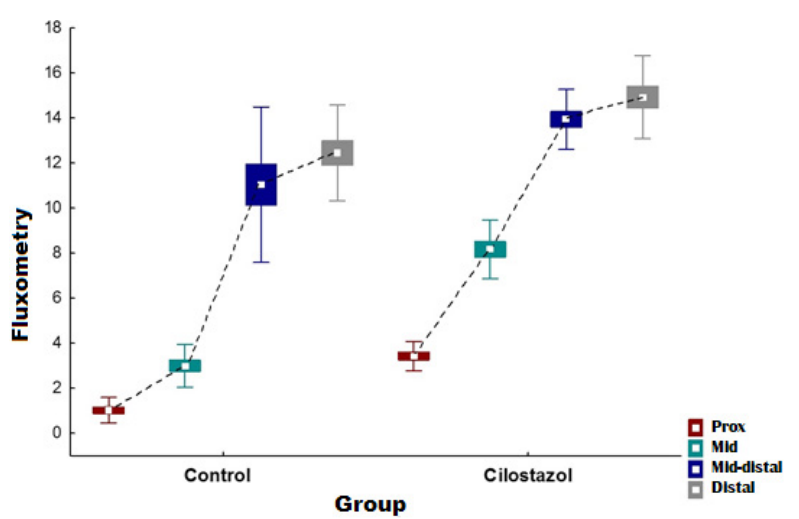

Figure 10 - Flow diagram in each of the regions for each of the groups.

\section{- Discussion}

There are two surgical procedures for the treatment of degloving injuries. The first consists of cleaning the wound and repositioning the flap to its original position; the second, cleaning the wound and resecting the flap, with partial or total skin grafting from the flap, followed by grafting on the flap in initial care. The success of the treatment depends on some factors, such as the time elapsed from the trauma (greater or less than 24 hours), the presence of hemodynamic instability and the viability of the avulsion flap ${ }^{5}$. Surgical repositioning of the flap, supposedly quicker and more direct, may result in partial or total necrosis of the flap ${ }^{10}$.

By repositioning and suturing the avulsed flap to its original position, drugs that increase the viability of this flap could be used to decrease the area of necrosis.

Kim et al. ${ }^{12}$ reported that oral administration of Cilostazol plus aspirin effectively increased blood flow in thrombosed anastomoses in the external iliac artery of rats. Nakamura et al. ${ }^{13}$ demonstrated that Cilostazol induces vasodilation in the thoracic artery of rats by increasing nitrous oxide (NO) production in aortic endothelial cells. Nitrous oxide plays an important role in the physiology of the flap after elevation and acts directly on vascular smooth muscle causing arterial vasodilation. Many studies have evaluated the effect of Cilostazol on nitrous oxide synthesis and have demonstrated that it potentiates nitrous oxide synthesis induced by interleukin-1 beta (IL-1 beta), probably via CAMP-dependent pathways ${ }^{14,15}$. Cilostazol also appears to 
attenuate cytokine-induced expression of iNOS (NO synthase protein expression) and increase the concentration of nitrite, which is a stable metabolite of nitrous oxide ${ }^{15,16}$. Some studies have demonstrated an advantage in the topical application of Cilostazol, which inhibits the intimal hyperplasia of vein grafts in rat models ${ }^{17}$ and increases blood flow in the skin of rabbits ${ }^{18}$. Most studies published in the literature demonstrate the effect of Cilostazol on increased blood flow. However, the effect of this drug on the evolution of skin-repellent flaps has not yet been established.

In the present study, Cilostazol was used as adjuvant therapy in the treatment of degloving injuries and postoperative enteral administration was associated with increased blood flow and lower percentage of necrotic area in the flap. Through objective methods (Doppler flowmetry and planimetry), it has been shown that there is an inverse correlation between the blood flow and the percentage of the area of necrosis, this relationship being more evident the more proximal in the flap. Doppler flow assessment also showed a greater mean blood flow in the flaps of the Cilostazol group, which may justify the smaller area of necrosis in the study group compared to the control group.

In the literature, several studies analyze the effect of drugs on the evolution of randomized non-degloving flaps ${ }^{19-21}$. Studies evaluating the influence of substances on the development of degloving injuries are scarce.

Oztuna et al. ${ }^{22}$ developed a model of degloving injuries in rats. After detachment of the flap by manual traction and re-suturing to its original bed, the study group received pentoxifylline ( $25 \mathrm{mg} / \mathrm{kg} /$ day) intraperitoneally for 10 days. On the 21st postoperative day, the authors resected the area of the degloving flap and examined it histopathologically. The epithelium of the control group presented loss of the superficial layer of epidermis and intense inflammatory infiltrate in the dermis. The epithelium of the pentoxifylline group recovered normal thickness and did not present any inflammatory infiltrate.

Michelski et al. ${ }^{9}$ analyzed the influence of three drugs on the development of degloving skin flaps in an animal model similar to that developed in our study. Pentoxifylline - a drug with the property of improving tissue blood flow by increasing the plasticity of red blood cells - reduced the area of necrosis in avulsed cutaneous flaps of rats by $21.64 \%$. Another drug analyzed was allopurinol, an antioxidant drug that acts as an inhibitor of the enzymes responsible for the formation of free radicals. Using an intraperitoneal $45 \mathrm{mg} / \mathrm{kg}$ dose of allopurinol, there was a $28.49 \%$ decrease in the total necrotic area in the study group compared to the necrotic area in the control group; the percentage of total necrotic area in the control group was $63.34 \%$, and the percentage of the necrotic area using allopurinol was $34.85 \%$. The third drug studied was enoxaparin, a low molecular weight heparin with an anticoagulant effect responsible for preventing the formation of thrombin. The findings showed a decrease of $30.63 \%$ of the tissue necrosis rate in the flap ${ }^{9}$. Pentoxifylline, allopurinol and enoxaparin demonstrated the ability to reduce the area of necrosis in the flap; however, with necrotic areas in flaps in the study group greater than the values obtained in the present study using Cilostazol (16.6\% vs. 41.7\%, 34.85\%, 32.71\%, respectively) ${ }^{9}$.

Regarding the methods used to obtain the results, both planimetry and Doppler flowmetry are objective, reliable and reproducible methods for other studies. These features provide credibility to the results found in the present study, in addition to possible comparison with other drugs in the near future.

Despite the promising findings in cutaneous flaps of rats, it is important to consider that rat skin is different from human 
skin, mainly because it has a layer of striated muscle located between the dermis and subcutaneous adipose tissue (Panniculus carusus muscle) $)^{23}$, which may be responsible for increased blood flow and lower rates of cutaneous necrosis in these mammals. Therefore, the direct comparison of degloving injuries in rats and in humans is difficult ${ }^{24}$. Clinical trials with degloving injuries in human skin may confirm the study's favorable findings.

\section{Conclusion}

Postoperative enteral administration of Cilostazol increased blood flow in the flaps secondary to degloving injuries and decreased the total area of necrosis in an experimental model in rats.

\section{References}

1. Morris M, Schreiber MA, Ham B. Novel Management of closed degloving injuries. J Trauma. 2009;67(4):E121-3. PMID: 19820564.

2. Milcheski DA, Ferreira MC, Nakamoto HA, Gemperli PTR. Tratamento cirúrgico de ferimentos descolantes nos membros inferiores - proposta de protocolo de atendimento. Rev Col Bras Cir. 2010;37(3): p.199-203. doi: 10.1590/S010069912010000300007.

3. Jeng SF, Hsieh $\mathrm{CH}$, Kuo YR, Wei FC. Technical refinement in the management of circumferentially avulsed skin of the leg. Plast Reconstr Surg. 2004;114(5):1225-7. PMID: 9385954.

4. Guimarães MVTN, Moreira GHG, Rocha LP, Nicoluzzi JEL, de Souza CJF, Repka JCD. $\mathrm{L}$-arginine action in cutaneous flap evolution under nicotine exposure in rats. Rev Col Bras Cir. 2013;40(1):49-54. PMID: 23538539.

5. Nickerson TP, Zielinski MD, Jenkins DH, Schiller HJ. The Mayo Clinic experience with morel-lavallée lesions: establishment of a practice management guideline. J Trauma Acute Care Surg. 2014;76(2):493-7. PMID: 24458056.

6. Kamiya T, Sakaguchi S. Hemodynamic effects of the antithrombotic drug cilostazol in chronic arterial occlusion in the extremities. Arzneimittelforschung. 1985;35:1201-3. PMID: 4074435.

7. Ikeda $Y$, Kikuchi M, Murakami H, Satoh K, Murata M, Watanabe K, Ando Y. Comparison of the inhibitory effects of cilostazol, acetylsalicylic acid and ticlopidine on platelet functions ex vivo. randomized, double-blind cross-over study. Arzneimittelforschung. 1987;37:563-6. PMID: 2956957.

8. Yasuda K, Sakuma M, TanabeT. Hemodynamic effect of cilostozol on increasing peripheral blood flow in arteriosclerosis obliterans. Arzneimittelforschung. 1985;35:1198-200. PMID: 4074434.

9. Milcheski DA, Ferreira MC, Nakamoto HA, Tuma Jr P. Development of an experimental model of degloving injury in rats. Rev Bras Cir Plást. 2012;27(4):514-7. doi: 10.1590/ S1983-51752012000400006.

10.Salles Júnior GS, Melo RC, Schmidt FR, Greca $\mathrm{FH}$, Dietz U, Araújo U,Machado C, Malafaia O, Nassif PA, Marcondes JRF. Avaliação da exposição e interrupção da nicotina em tempos diferentes na evolução de retalho cutâneo ao acaso de dorso de ratos por meio de fluxometria a laser e de picrosirius. Rev Bras Cir. Plást. 2008;23(4):322-327 PMID 23538539

11.Oliva A, Vernooy K, Cooter R, David DJ, Pascali V. Helmet-induced neck degloving in a motorcyclist. J Trauma Inj Infect Crit Care. 2005;58(2):370-1. doi: 10.1097/01. TA.0000152601.83858.72.

12. Kim SH, Chang HW, Choi TH, Kim JH, Son D, Han K, Lee SY, Park J, Suh EH, Park SH. Cilostazol effectively reduces the decrease of flow volume in a thrombotic anastomosis model in a rat: a novel application of ultrasonography for evaluation. Ann Plast Surg. 2010;64:482-6. PMID: 20224350.

13. Nakamura T, Houchi H, Minami A, Sakamoto S, Tsuchiya K, Niwa Y, Minakuchi K, Nakaya Y. Endothelium-dependent relaxation by Cilostazol, a phosphodiesterase III inhibitor, on rat thoracic aorta. Life Sci. 2001;69:170915. PMID: 11665832.

14.Ito C, Kusano E, Akimoto T, Takeda S, Sasaki $\mathrm{N}$, Umino $\mathrm{T}$, Limura $\mathrm{O}$, Ando $\mathrm{Y}$, Asano $\mathrm{Y}$. Cilostazol enhances IL-1beta-induced NO production and apoptosis in rat vascular smooth muscle via PKA-dependent 
pathway. Cell Signal. 2002;14:625-32. PMID: 11955955.

15.Ikeda U, Ikeda $M$, Kano $S$, Kanbe $T$, Shimada K. Effect of Cilostazol, a cAMP phosphodiesterase inhibitor, on nitric oxide production by vascular smooth muscle cells. Eur J Pharmacol. 1996;314:197-202. PMID: 8957237.

16.Aoki C, Hattori Y, Tomizawa A, Jojima T, Kasai $\mathrm{K}$. Anti-inflammatory role of Cilostazol in vascular smooth muscle cells in vitro and in vivo. J Atheroscler Thromb. 2010;17:503-9. PMID: 20179359.

17. Yamamoto K, Onoda K, Sawada Y, Fujinaga K, Imanaka-Yoshida K, Yoshida T, Shimpo H. Locally applied Cilostazol suppresses neointimal hyperplasia and medial thickening in a vein graft model. Ann Thorac Cardiovasc Surg. 2007;13:322-30. PMID: 15354092.

18.Ono I, Gunji H, Suda K, Kaneka F. Effects of Cilostazol lotion on blood flow in rabbit skin. J Dermatol Sci. 1994;7:79-83. PMID: 8060917.

19. Bittencourt RC, Biondo-Simões ML, Paula JB, Martynetz J, Groth A. Influence of minoxidil on ischemic cutaneous flaps in rats. Acta Cir Bras. 2005;20(6):450-4. doi: 10.1590/ S0102-86502005000600010.

20.Gideroglu K, Alagoz S, Uygur F, Evinc R,
Celikoz B, Bugdayci G. Effects of nebivolol on skin flap survival: a randomized experimental study in rats. Curr Ther Res Clin Exp. 2008;69(5):449-58. doi: 10.1016/j. curtheres.2008.10.001.

21.Davies BW, Lewis RD, Pennington G. The impact of vasodilators on random-pattern skin flap survival in the rat following mainstream smoke exposure. Ann Plast Surg. 1998;40(6):630-6. PMID: 9641282.

22.Oztuna V, Eskandari MM, Unal S, Colak M, Karabacak T. The effect of pentoxifylline in treatment of skin degloving injuries: an experimental study. Injury. 2006;37:638-41. PMID: 16769312.

23.Wojciechowicz K, Gledhill K, Ambler CA, Manning CB, Jahoda CA. Development of the mouse dermal adipose layer occurs independently of subcutaneous adipose tissue and is marked by restricted early expression of FABP4. PLoS One. 2013;8:e59811. PMID: 23555789.

24.Burusapat C, Paengnoi J, Satayasoontorn K. An experimental study of the effect of pre-operative administration of cilostazol on random skin flap survival in rats: double blinded randomized controlled trial. Ann Surg Innov Res. 2015;9:2. doi: 10.1186/ s13022-015-0011-4.

\section{Correspondence:}

André Pazio

Rua Castro Alves, 785/82

80240-270 Curitiba - PR Brasil

Tel.: (55 41)98843-9090

drandrepazio@gmail.com

Received: Dec 16, 2017

Review: Feb 18, 2018

Accepted: Mar 20, 2018
Conflict of interest: none

Financial source: none

\begin{abstract}
${ }^{1}$ Research performed at Laboratory of Surgical Technique, Department of Surgery, Pontificia Universidade Católica do Paraná (PUC-PR), Curitiba-PR, Brazil.
\end{abstract}

